\title{
Clinicopathologic Characteristics of CD99-Positive Diffuse Large B-Cell Lymphoma
}

\author{
Sang Pyo Lee ${ }^{\mathrm{a}}$ Sanghui Park ${ }^{\mathrm{b}}$ Jinny Park ${ }^{\mathrm{a}}$ Junshik Hong ${ }^{\mathrm{a}}$ Young Hyeh Ko $^{\mathrm{c}}$ \\ Departments of a Medicine and ${ }^{b}$ Pathology, Gil Medical Center, Gachon University of Medicine and Science, \\ Incheon, and 'Department of Pathology, Samsung Medical Center, Sungkyunkwan University School of Medicine, \\ Seoul, Korea
}

\section{Key Words}

Anaplastic carcinomas $\cdot$ CD99 $\cdot$ Diffuse large B-cell carcinomas $\cdot$ Germinal center B cells $\cdot$ Lymphomas

\begin{abstract}
Background: CD99 immunoreactivity has been documented in a variety of tumors, including lymphoid malignancies such as anaplastic large-cell lymphomas. However, few studies have investigated the prognostic impact of CD99 in diffuse large B-cell lymphoma (DLBCL). Methods: Using conventional paraffin embedding, immunoperoxidase staining and tissue microarrays, we retrospectively investigated CD99 expression in 155 DLBCL patients. Results: Of the 155 DLBCL patients, 60 (38.7\%) were positive for CD99. CD99 positivity was significantly associated with advanced stage ( $p<0.01)$, higher risk group according to the International Prognostic Index risk score $(p<0.01)$ and non-germinal center $B$ cell-like type $(p=0.01)$. The difference in progressionfree survival (PFS) between CD99+ and CD99- groups was statistically significant $(p=0.04)$, even though the difference in overall survival was not $(p=0.74)$. Multivariate analysis demonstrated that CD99 expression was marginally correlated with PFS. Conclusion: To the best of our knowledge, this is the first report on the clinicopathologic characteristics of CD99+ DLBCL, particularly unique clinicopathologic features.

Copyright $\odot 2010$ S. Karger AG, Basel
\end{abstract}

\section{Introduction}

Diffuse large B-cell lymphoma (DLBCL) is the most common subtype of non-Hodgkin's lymphoma and is considered to have heterogeneous biological characteristics [1]. Therefore, identification of a high-risk group or a specific subtype of DLBCL is particularly important. Assessment of the prognostic parameters at the initial diagnosis may enable implementation of risk-based stratification of therapy and facilitate the identification of those who may benefit from early intensive therapy. Recently, CD99 expression has been demonstrated in DLBCL and other non-Hodgkin's lymphomas, and Sung et al. [2] occasionally identified recurrent DLBCL patients who were positive for CD99 and resistant to chemotherapy. These findings prompted us to determine clinicopathologic characteristics of CD99-expressing DLBCL.

CD99 is a membrane epitope best known for its role as a diagnostically useful marker of Ewing sarcoma/primitive neuroectodermal tumor in childhood [3]. CD99 is

S.P.L. and S.P. are both first authors of this paper.

We have no conflict of interest to declare. This study was accepted for poster presentation at the XVth Meeting of the European Association for Hematopathology in Uppsala, Sweden.

\section{KARGER}

Fax +41613061234 E-Mail karger@karger.ch www.karger.com
Young Hyeh Ko, MD, PhD

Department of Pathology, Samsung Medical Center

Sungkyunkwan University School of Medicine, 50 Ilwon-dong Kangnam-Gu Seoul 135-710 (Korea)

Tel. +82 23410 2752, Fax +82 234100025 , E-Mail yhko310@skku.edu 
also present in a variety of other tumors, including some carcinomas [4-6], testicular and ovarian sex cord tumors [7-10], synovial sarcomas [11, 12] and miscellaneous other tumors. Among hematopoietic neoplasms, lymphoblastic lymphomas/leukemias [13-15], acute myeloid leukemias [16] and anaplastic large-cell lymphomas have shown CD99 immunoreactivity (54.0-64.4\%) [2, 17]. The impact of CD99 positivity on treatment outcome has not been observed in DLBCL previously. In order to define the prognostic impact of CD99 expression in DLBCL, we retrospectively investigated $155 \mathrm{DLBCL}$ patients in whom biopsy specimens were available for further pathologic examination.

\section{Patients and Methods}

\section{Patients}

The criteria for inclusion were as follows: (1) pathologically confirmed diagnosis of DLBCL according to the WHO classification [1]; (2) a complete set of clinical data being available, and (3) adequate paraffin-embedded biopsy specimen for CD99 immunohistochemistry. A complete set of clinical information in this analysis included patient demographics, treatment type, treatment outcome and vital status.

Tissue Microarray Construction

Tissue microarray (TMA) blocks were constructed for 155 cases of DLBCL using a tissue array (ISU abxis, Seoul, Korea). The available hematoxylin-eosin-stained slides for each case were reviewed by the pathologists, and representative areas were selected for TMA construction. Each individual case was represented by 2 tumor cores of $1.0 \mathrm{~mm}$ taken from the original paraffin blocks. Serial $4-\mu \mathrm{m}$ sections were cut from the TMA blocks and used for CD99 immunohistochemical analysis. Other immunohistochemical stains (Bcl-2, Bcl-6, CD10 and MUM-1) were performed using whole sections from the original paraffin blocks.

\section{Histology}

All pathologic specimens were reviewed by an experienced pathologist (Y.H.K.) and reclassified in accordance with the WHO criteria for pathologic diagnosis. Immunohistochemical analysis of the paraffin sections was performed using monoclonal and polyclonal antibodies to detect lineage-specific and lineage-characteristic antigens. Cases of confirmed follicular architecture and transformed lymphoma were excluded from this study. Immunophenotyping was performed using a panel of monoclonal antibodies, including antibodies against CD99, CD10, Bcl-6 and MUM-1 (all from Dakopatts, Copenhagen, Denmark). A cutoff value of $10 \%$ positive cells was used for CD99 staining. Using these markers, DLBCL was categorized into two subgroups, the germinal center B-cell-like (GCB) and non-GCB type, using the algorithm proposed by Hans et al. [18].

\section{Treatment}

Patients received one of the following initial treatment modalities: (1) an anthracycline-containing chemotherapeutic regimen; (2) a non-anthracycline-containing chemotherapeutic regimen, and (3) supportive care only. The anthracycline-based regimens used were as follows: CHOP (cyclophosphamide, doxorubicin, vincristine and prednisolone; $n=102)$, rituximabCHOP $(n=21)$ and others $(n=26)$. Four patients received best supportive care only. Treatment response was assessed according to standard response criteria [19].

\section{Statistical Analysis}

Overall survival (OS) and progression-free survival (PFS) were estimated using the Kaplan-Meier product-limit method. OS was calculated from the date of diagnosis to the date of death from any cause or the last follow-up. PFS was measured from the date of diagnosis to the date of the first documented progression, death or the last follow-up visit. Survival rates were compared for statistical differences using the log-rank or Breslow (generalized Wilcoxon) tests. Continuous biologic variables were dichotomized. A backward stepwise Cox regression analysis was performed to delineate prognostic factors at multivariate level and all hazard ratios were adjusted for age. A value of $p<0.05$ was considered statistically significant and all $p$ values correspond to twosided significance tests.

\section{Results}

\section{Patient Characteristics and CD99}

Immunohistochemical Results

A total of 155 patients pathologically diagnosed with DLBCL between September 1994 and December 2005 were included in this analysis. All patients were Korean, immunocompetent and negative for anti-human immunodeficiency virus antibody. Baseline characteristics are summarized in table 1 . In all 155 cases, paraffin-embedded tissue was available for CD99 immunohistochemical analysis, and 60 (38.7\%) cases were identified as CD99 positive. The staining pattern of CD99 was predominantly membranous (fig. 1,2).

CD99 positivity was significantly associated with advanced stage $(p<0.01)$, a higher risk group according to the International Prognostic Index risk score $(\mathrm{p}<0.01)$ and non-GCB group $(\mathrm{p}=0.01)$. There were no significant differences in the distribution of primary treatment modalities between CD99+ and CD99- groups ( $\mathrm{p}=0.12)$. Of the $132(85.2 \%)$ patients in whom treatment responses were available (CD99-, $\mathrm{n}=83$; CD99+, $\mathrm{n}=49$ ), 120 responded to the initial therapy (overall response rate, 90.9\%). The overall response rate to the initial treatment was not significantly different between CD99+ (44 of 49, $89.8 \%$ ) and CD99- DLBCL patients (76 of $83,91.6 \%$; $\mathrm{p}=$ $0.73)$. 
Table 1. Baseline characteristics of DLBCL patients according to CD99 expression

\begin{tabular}{|c|c|c|c|c|}
\hline Characteristics & All patients & CD99- & CD99+ & $\mathrm{p}$ \\
\hline Total cases, n (\%) & $155(100)$ & $95(61.3)$ & $60(38.7)$ & \\
\hline$\leq 60$ years & $104(67.1)$ & $65(68.4)$ & $39(65.0)$ & 0.66 \\
\hline$>60$ years & $51(32.9)$ & $30(31.6)$ & $21(35.0)$ & \\
\hline Median age, years & 57 & 53 & 55 & \\
\hline Sex, n (\%) & & & & 0.58 \\
\hline Males & $87(43.9)$ & $55(57.9)$ & $32(53.3)$ & \\
\hline Females & $68(56.1)$ & $40(42.1)$ & $28(46.7)$ & \\
\hline Performance status, n (\%) & & & & 0.11 \\
\hline ECOG 0-1 & $128(87.7)$ & $82(91.1)$ & $46(82.1)$ & \\
\hline ECOG 2-4 & $18(12.3)$ & $8(8.9)$ & $10(17.9)$ & \\
\hline Initial presentation, $\mathrm{n}(\%)$ & & & & 0.43 \\
\hline Nodal & $47(32.2)$ & $27(31.0)$ & $20(33.9)$ & \\
\hline Extranodal & $38(26.0)$ & $26(29.9)$ & $12(20.3)$ & \\
\hline Nodal + extranodal & $61(41.8)$ & $34(39.1)$ & $27(45.8)$ & \\
\hline Ann Arbor stage, n (\%) & & & & $<0.01$ \\
\hline Limited (I-II) & $103(71.5)$ & $73(83.0)$ & $30(53.6)$ & \\
\hline Advanced (III-IV) & $41(28.5)$ & $15(17.0)$ & $26(46.4)$ & \\
\hline LDH, n (\%) & & & & 0.13 \\
\hline$\leq \mathrm{ULN}$ & $87(58.4)$ & $57(63.3)$ & $30(50.8)$ & \\
\hline$>\mathrm{ULN}$ & $62(41.6)$ & $33(36.7)$ & $29(49.2)$ & \\
\hline IPI risk groups, $\mathrm{n}(\%)$ & & & & $<0.01$ \\
\hline Low/low intermediate & $112(81.2)$ & $74(88.1)$ & $38(70.4)$ & \\
\hline High intermediate/high & $26(18.8)$ & $10(11.9)$ & $16(29.6)$ & \\
\hline B symptom, n (\%) & & & & 0.33 \\
\hline Positive & $28(19.2)$ & $15(16.7)$ & $13(23.2)$ & \\
\hline Negative & $118(80.8)$ & $75(83.3)$ & $43(76.8)$ & \\
\hline Bone marrow involvement, $\mathrm{n}(\%)$ & & & & 0.74 \\
\hline Positive & $9(6.2)$ & $6(6.7)$ & $3(5.4)$ & \\
\hline Negative & $136(93.8)$ & $83(93.3)$ & $53(94.6)$ & \\
\hline Primary treatment, n (\%) & & & & $0.12^{\mathrm{a}}$ \\
\hline Anthracycline-based chemotherapy with or without radiotherapy & $102(66.7)$ & $67(72.0)$ & $35(58.3)$ & \\
\hline Rituximab + CHOP with or without radiotherapy & $21(13.7)$ & $10(10.8)$ & $11(18.3)$ & \\
\hline Non-anthracycline-based chemotherapy & $26(17.0)$ & $14(15.1)$ & $12(20.0)$ & \\
\hline Best supportive care only & $4(2.6)$ & $2(2.2)$ & $2(3.3)$ & \\
\hline Response to front-line chemotherapy $(n=132)^{b}$ & & & & 0.73 \\
\hline Complete remission or partial remission & $120(90.9)$ & $76(91.6)$ & $44(89.8)$ & \\
\hline Stable disease or progressive disease & $12(9.1)$ & $7(8.4)$ & $5(10.2)$ & \\
\hline Histologic subtype & & & & 0.01 \\
\hline $\mathrm{GCB}$ & $68(44.7)$ & $49(52.7)$ & $19(32.2)$ & \\
\hline Non-GCB & $84(55.3)$ & $44(47.3)$ & $40(67.8)$ & \\
\hline
\end{tabular}

For the following patient characteristics data were missing: performance status $(n=9)$, initial disease presentation $(n=9)$, Ann Arbor stage $(n=11)$, LDH level $(n=6)$, International Prognostic Index (IPI) risk score $(n=17)$, B symptoms $(n=9)$, bone marrow involvement $(n=10)$ and histologic subtype $(n=3)$. ULN = Upper limit of normal.

${ }^{a}$ Non-anthracycline-based chemotherapy versus anthracycline-based chemotherapy.

b 132 patients were assessable for response.

\section{Impact of CD99 Positivity on Survival}

After a median follow-up period of 38 months (range, 1-156 months), 5-year OS and 5-year PFS were 66.7 and $58.1 \%$, respectively. The difference in PFS between CD99+ and CD99- groups was statistically significant $(\mathrm{p}=0.04$; fig. 3b), even though the difference in OS was not ( $\mathrm{p}=$ 0.74 ; fig. 3a). Subsequently, we performed subgroup analyses according to sex (male vs. female) and GCB versus non-GCB status (fig. 4, 5). Male CD99+ DLBCL patients disclosed a more rapidly deteriorating clinical course 


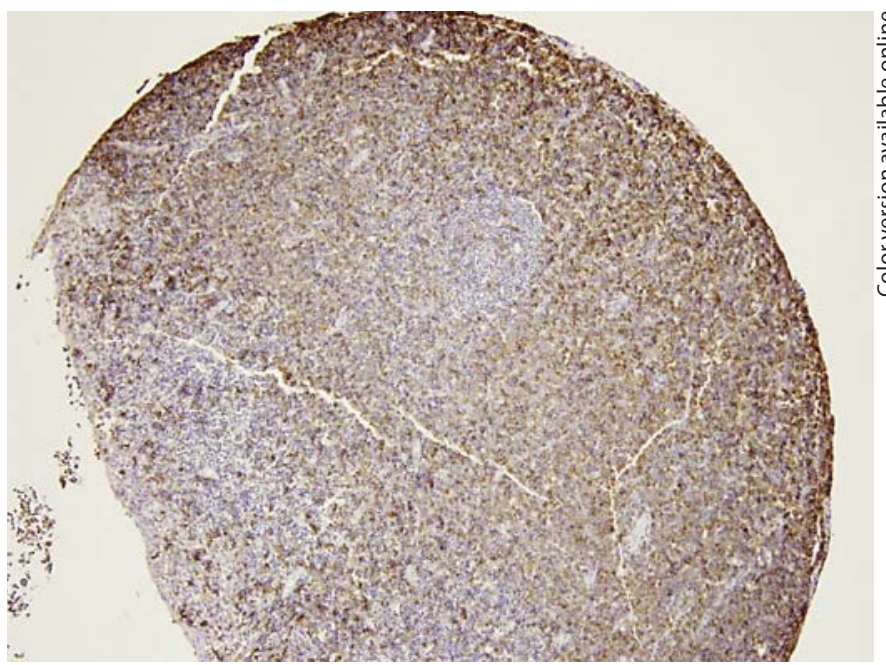

Fig. 1. CD99 expression of DLBCL in TMA (immunoperoxidase staining, $\times 100)$.

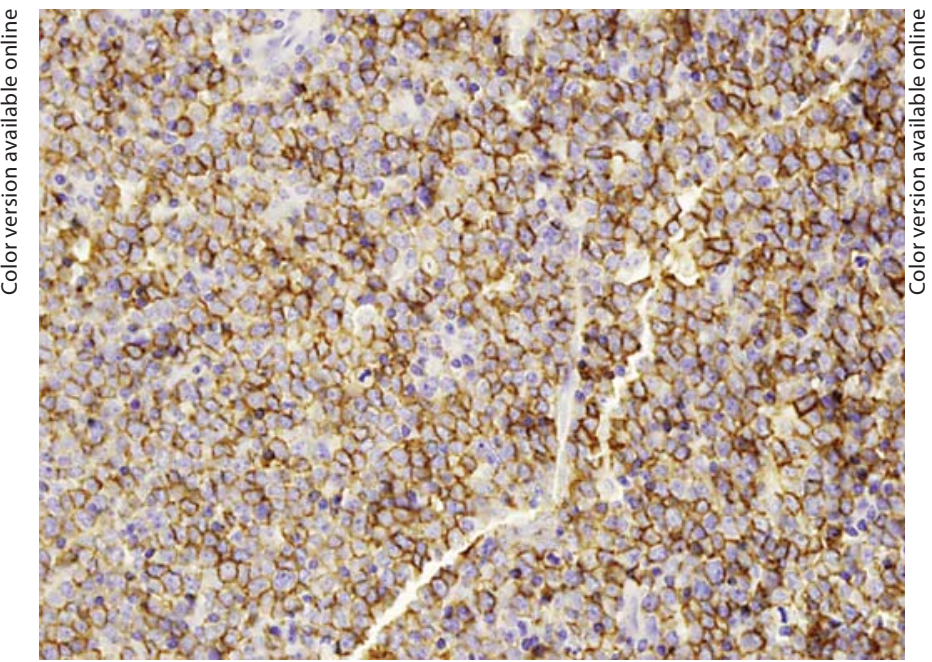

Fig. 2. Membranous expression of CD99 in DLBCL (immunoperoxidase staining, $\times 400)$.

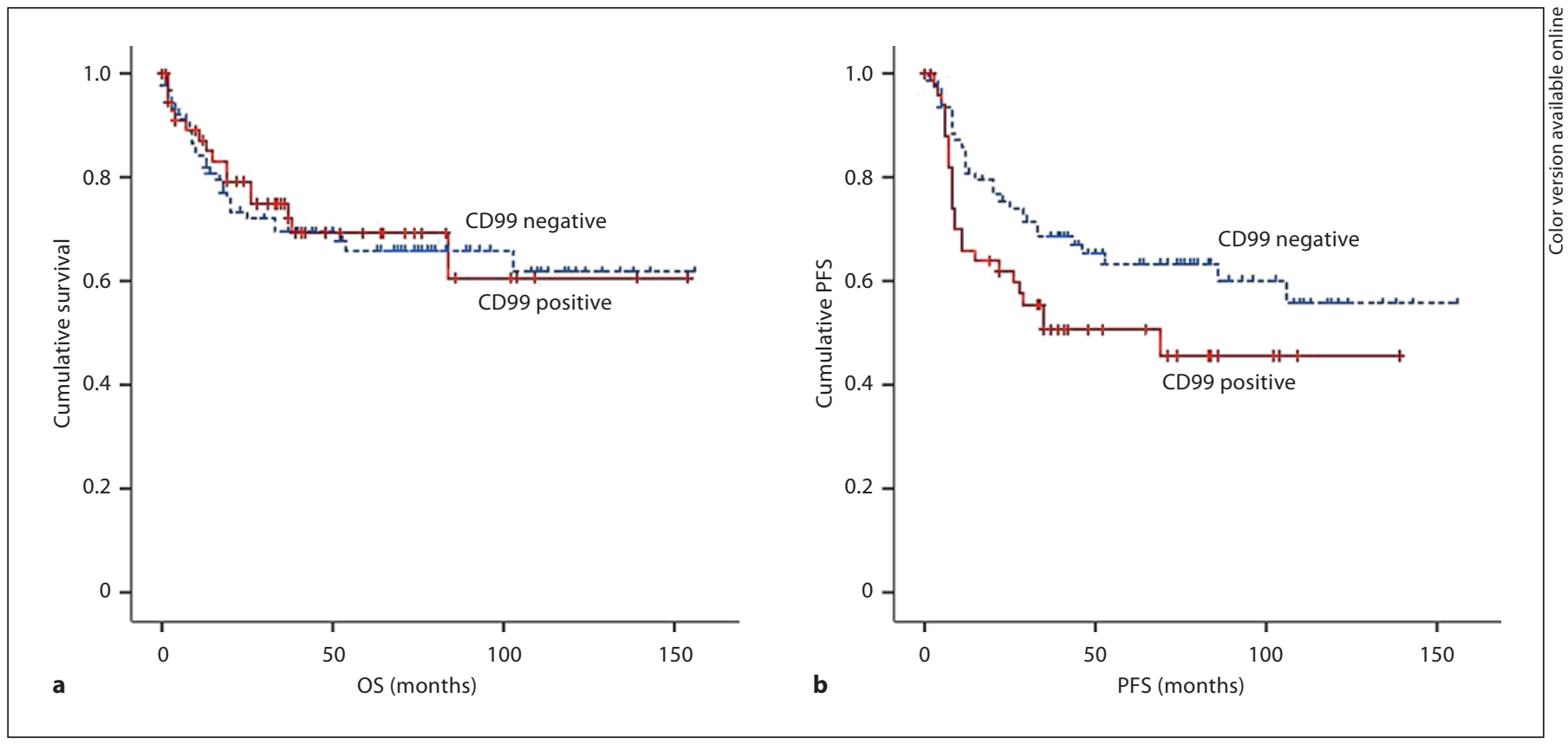

Fig. 3. Patient OS (a) and PFS (b) according to CD99 positivity in all patients. $\mathbf{a} \mathrm{p}=0.74 . \mathbf{b} \mathrm{p}=0.04$ (Breslow test) and $\mathrm{p}=0.058$ (log-rank test).

compared to CD99- DLBCL patients in terms of PFS, which was statistically significant ( $\mathrm{p}=0.02$; fig. $4 \mathrm{~b})$. In non-GCB DLBCL patients, CD99 positivity had a statistically significant adverse effect on PFS ( $p=0.01$; fig. $5 b$ ). However, CD99 positivity did not influence OS in female and GCB DLBCL patients (fig. 4a, 5a).

\section{Prognostic Factor Analyses}

The results of univariate and multivariate OS analyses, including CD99 expression, performance status, lactic dehydrogenase (LDH) level, sex, age group, presence of B symptoms and Ann Arbor stage, are summarized in table 2. In the univariate analysis for OS, performance 


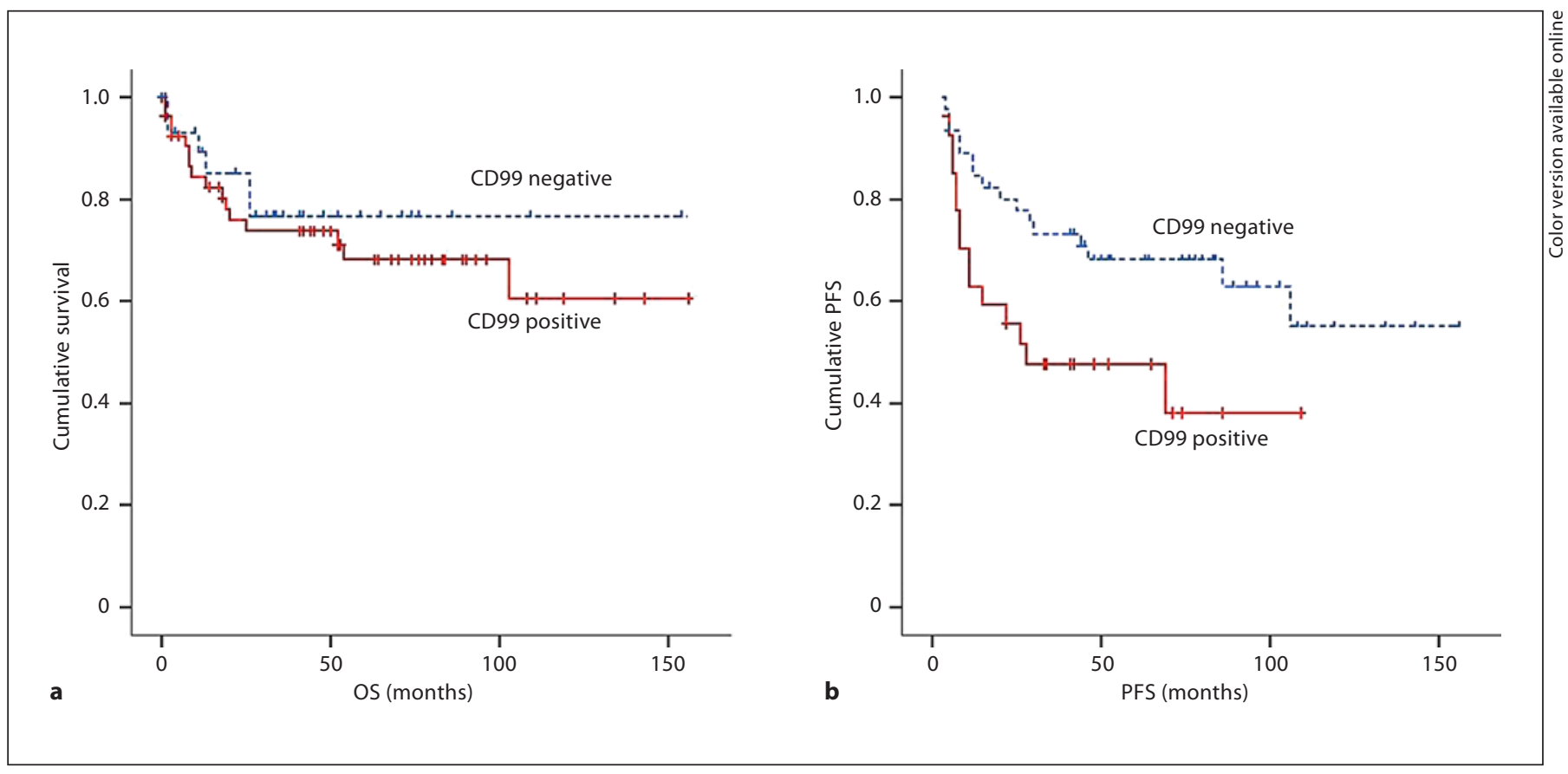

Fig. 4. Patient OS (a) and PFS (b) according to CD99 positivity in male patients. a $\mathrm{p}=0.54$. $\mathbf{b} \mathrm{p}=0.02$ (Breslow test) and $\mathrm{p}=0.03$ (log-rank test).

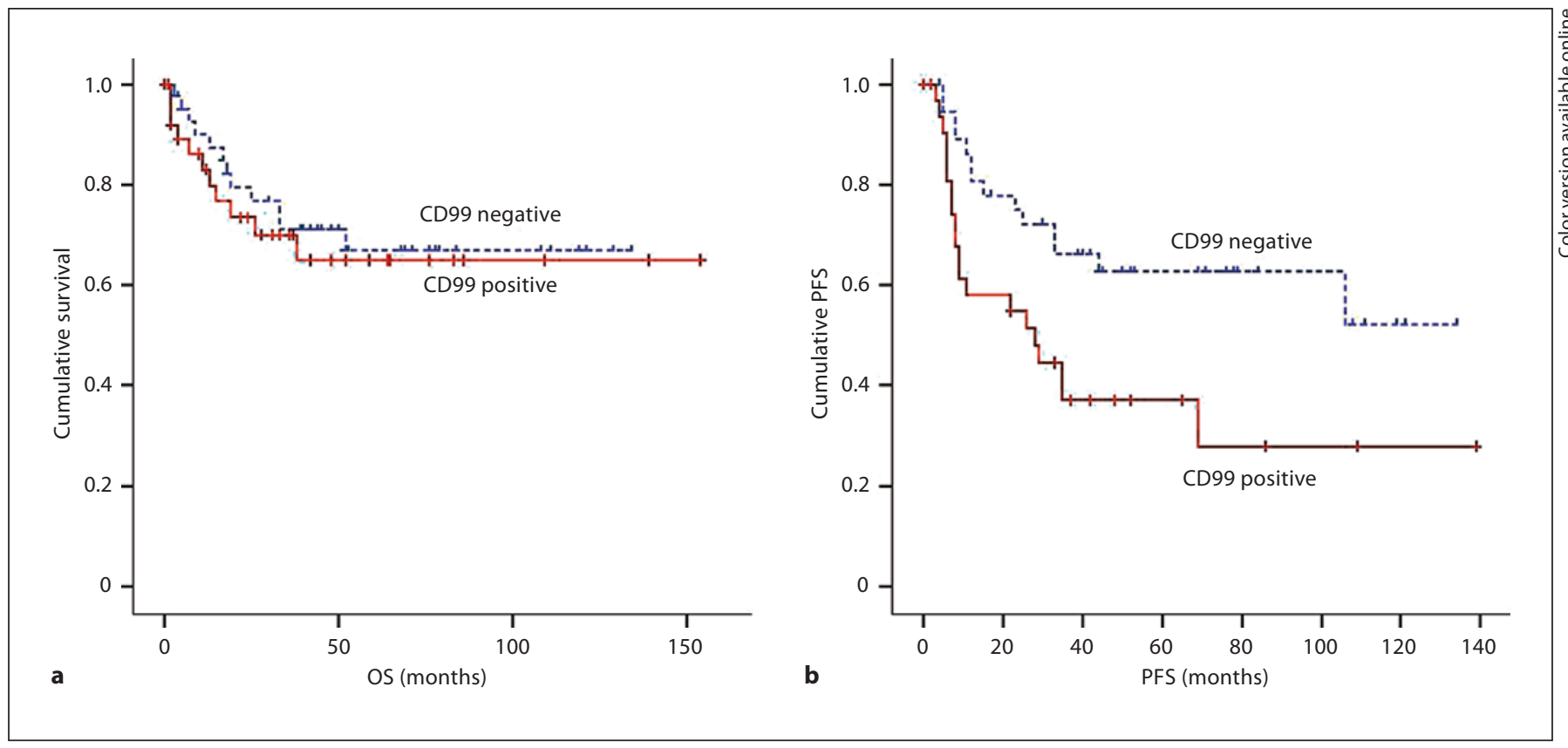

Fig. 5. Patient OS (a) and PFS (b) according to CD99 positivity in the non-GCB group. a $\mathrm{p}=0.47$. $\mathbf{b} \mathrm{p}=0.01$ (Breslow and log-rank tests). 
Table 2. Prognostic factors affecting OS in 155 patients with DLBCL

\begin{tabular}{|c|c|c|c|c|c|}
\hline \multirow[t]{2}{*}{ Variables } & \multirow{2}{*}{$\begin{array}{l}\text { Unfavorable } \\
\text { factor }\end{array}$} & \multicolumn{2}{|l|}{ Univariate } & \multicolumn{2}{|l|}{ Multivariate } \\
\hline & & hazard ratio $(95 \% \mathrm{CI})$ & $\mathrm{p}$ & hazard ratio $(95 \% \mathrm{CI})$ & $\mathrm{p}$ \\
\hline CD99 expression & positive & $0.932(0.506-1.718)$ & 0.82 & ND & ND \\
\hline Sex & female & $1.337(0.745-2.400)$ & 0.33 & ND & ND \\
\hline B symptom & present & $1.363(0.671-2.768)$ & 0.39 & ND & ND \\
\hline Histologic subtype & non-GCB & $1.011(0.559-1.828)$ & 0.97 & ND & ND \\
\hline $\mathrm{LDH}$ & high & $2.242(1.221-4.114)$ & $<0.01$ & $1.808(0.945-3.468)$ & 0.075 \\
\hline Performance status & ECOG 2-4 & $3.886(1.990-7.588)$ & $<0.01$ & $3.047(1.456-6.379)$ & $<0.01$ \\
\hline Age & $>60$ years & $2.573(1.426-4.642)$ & $<0.01$ & $2.308(1.241-4.293)$ & $<0.01$ \\
\hline Ann Arbor stage & III/IV & $2.940(1.600-5.401)$ & $<0.01$ & $1.993(1.028-3.866)$ & 0.041 \\
\hline
\end{tabular}

$\mathrm{CI}=$ Confidence interval; $\mathrm{ND}=$ not done.

Table 3. Prognostic factors affecting PFS in 155 patients with DLBCL

\begin{tabular}{|c|c|c|c|c|c|}
\hline \multirow[t]{2}{*}{ Variables } & \multirow{2}{*}{$\begin{array}{l}\text { Unfavorable } \\
\text { factor }\end{array}$} & \multicolumn{2}{|l|}{ Univariate } & \multicolumn{2}{|l|}{ Multivariate } \\
\hline & & hazard ratio $(95 \% \mathrm{CI})$ & $\mathrm{p}$ & hazard ratio $(95 \% \mathrm{CI})$ & $\mathrm{p}$ \\
\hline CD99 expression & positive & $1.665(0.972-2.851)$ & 0.058 & - & - \\
\hline Sex & female & $0.988(0.576-1.696)$ & 0.97 & ND & ND \\
\hline B symptom & present & $1.459(0.767-2.773)$ & 0.25 & ND & ND \\
\hline Histologic subtype & non-GCB & $1.311(0.910-1.945)$ & 0.14 & ND & ND \\
\hline $\mathrm{LDH}$ & high & $1.755(1.028-2.995)$ & 0.04 & - & - \\
\hline Performance status & ECOG 2-4 & $1.976(0.929-4.199)$ & 0.08 & - & - \\
\hline Age & $>60$ years & $1.649(0.948-2.868)$ & 0.08 & - & - \\
\hline Ann Arbor stage & III/IV & $3.134(1.826-5.377)$ & $<0.01$ & $2.507(1.311-4.794)$ & $<0.01$ \\
\hline
\end{tabular}

$\mathrm{CI}=$ Confidence interval; ND = not done; $-=$ not applicable.

status, LDH level, age and stage were significantly associated with survival. In the multivariate analysis, patients with advanced performance status according to the Eastern Cooperative Oncology Group (ECOG 2-4), high LDH level, advanced stage and older age had a higher risk of death than patients with low performance status (ECOG 0-1), low LDH level, lower stage and younger age (table 2).

The results of univariate and multivariate PFS analyses, including CD99 expression, performance status, $\mathrm{LDH}$ level, sex, age, presence of B symptom and stage, are summarized in table 3 . In the univariate analysis, $\mathrm{LDH}$ and stage were significantly associated with survival. In the multivariate analysis, patients with stage III/IV tumors were at higher risk for disease progression than patients with stage I/II tumors.

\section{Discussion}

An analysis of 60 DLBCL patients with CD99 expression highlighted previously unrecognized features of this disease - advanced stage at onset, frequent association with poor International Prognostic Index components and non-GCB subtype. To the best of our knowledge, this work represents the first study to evaluate the significance of CD99 positivity on treatment outcome and survival in DLBCL patients. Even though this study does not provide a definite conclusion whether CD99+ DLBCL constitutes a distinct disease subtype or a group with a poor prognosis, CD99+ DLBCL appears to be a unique subgroup of DLBCL.

One previous study demonstrated that CD99 was overexpressed in $5.4 \%$ of DLBCL patients $(2 / 37)$ and the 
malignancy was considered immunoreactive for CD99 if diffuse cell membrane staining was observed in $>70 \%$ of tumor cells ( $10 \%$ cutoff value in present study) [2].

The staining pattern of CD99 was predominantly membranous. Three patients of our series showed cytoplasmic staining without membrane staining. Because only a membranous pattern is considered diagnostic for Ewing sarcoma and lymphoblastic lymphoma in most studies [2, 5-16], we only included cases with membrane staining.

Similar distribution of treatment modalities between CD99+ and CD99- patients (anthracycline-based chemotherapy; 66.7 vs. $72.0 \%$, respectively) was observed, with CD99+ DLBCL showing similar response to frontline chemotherapy compared to CD99- DLBCL. Only 21 patients had been treated with rituximab. Therefore, we did not analyze the relationship between CD99 and clinical outcome stratified by rituximab treatment. The therapeutic impact of adding rituximab to the first-line therapy in CD99+ DLBCL needs to be evaluated in the setting of well-designed clinical trials. Due to the retrospective nature of this study, stratification of therapy according to the CD99 status in DLBCL could not be firmly established.

Univariate analysis of survival indicated that CD99+ patients had significantly worse PFS compared to CD99patients $(\mathrm{p}=0.04$ by Breslow test and $\mathrm{p}=0.058$ by logrank test), even though OS was not statistically significant. The reason why OS was not statistically significant is not clear. However, this discrepancy can be explained by a relatively short median follow-up (38 months).
The issue of whether CD99+ DLBCL represents an independent disease entity remains unanswered and needs to be clarified in future studies. In addition, the number of CD99+ patients would have been 13, if the cutoff value of CD99 positivity was set at $70 \%$. The impact of CD99 overexpression in DLBCL should be validated in a study including a larger patient cohort.

The role of the CD99 molecule in the aggressiveness of CD99+ DLBCL remains to be elucidated.

The relatively high frequency of CD99 overexpression in DLBCL observed in this study is intriguing, raising the question of the potential role of CD99 in the pathogenesis and/or development of DLBCL. CD99 appears to mediate a distinctive apoptotic signal at a critical stage of thymocyte differentiation [20]. CD99 is also suggested to be an activation-related molecule which is upregulated in recently activated lymphocytes [21].

CD99+ DLBCL was associated with more advanced disease stage and non-GCB subtype $(\mathrm{p}<0.01$ and $\mathrm{p}=$ 0.01 , respectively) according to the criteria established by Hans et al. [18]. In this study, $67.8 \%$ of the cases were of the non-GCB subtype. These clinicopathologic characteristics may provide a clue to elucidate the aggressiveness of such DLBCL. The biologic and clinical implications of CD99 in DLBCL are worthy of further investigation.

In conclusion, our study provides new clinicopathologic information on CD99+ DLBCL, particularly unique clinicopathologic features. Further studies are needed to clarify the prognostic impact of CD99 overexpression.

\section{References}

1 World Health Organization Classification of Tumours of Haematopoietic and Lymphoid Tissues, ed 4. Lyon, International Agency for Research on Cancer, 2008.

-2 Sung CO, Ko YH, Park S, Kim K, Kim W: Immunoreactivity of CD99 in non-Hodgkin's lymphoma: unexpected frequent expression in ALK-positive anaplastic large cell lymphoma. J Korean Med Sci 2005;20:952-956.

>3 Hamilton G, Fellinger EJ, Schratter I, Fritsch A: Characterization of a human endocrine tissue and tumor-associated Ewing's sarcoma antigen. Cancer Res 1988;48:6127-6131.

$\checkmark 4$ Jung KC, Park WS, Bae YM, Hahn JH, Hahn K, Lee H, Lee HW, Koo HJ, Shin HJ, Shin HS, Park YE, Park SH: Immunoreactivity of CD99 in stomach cancer. J Korean Med Sci 2002;17:483-489.
5 Milanezi F, Pereira EM, Ferreira FV, Leitao D, Schmitt FC: CD99/MIC-2 surface protein expression in breast carcinomas. Histopathology 2001;39:578-583.

6 Yoo SH, Han J, Kim TJ, Chung DH: Expression of CD99 in pleomorphic carcinomas of the lung. J Korean Med Sci 2005;20:50-55.

$\checkmark 7$ Choi YL, Kim HS, Ahn G: Immunoexpression of inhibin alpha subunit, inhibin/activin betaA subunit and CD99 in ovarian tumors. Arch Pathol Lab Med 2000;124:563569.

8 Gordon MD, Corless C, Renshaw AA, Beckstead J: CD99, keratin, and vimentin staining of sex cord-stromal tumors, normal ovary, and testis. Mod Pathol 1998;11:769-773.
$>9$ Kommoss F, Oliva E, Bittinger F, Kirkpatrick CJ, Amin MB, Bhan AK, Young RH, Scully RE: Inhibin-alpha CD99, HEA125, PLAP, and chromogranin immunoreactivity in testicular neoplasms and the androgen insensitivity syndrome. Hum Pathol 2000;31:10551061.

10 Matias-Guiu X, Pons C, Prat J: Müllerian inhibiting substance, alpha-inhibin, and CD99 expression in sex cord-stromal tumors and endometrioid ovarian carcinomas resembling sex cord-stromal tumors. Hum Pathol 1998;29:840-845.

-11 Hartel PH, Fanburg-Smith JC, Frazier AA, Galvin JR, Lichy JH, Shilo K, Franks TJ: Primary pulmonary and mediastinal synovial sarcoma: a clinicopathologic study of 60 cases and comparison with five prior series. Mod Pathol 2007;20:760-769. 
-12 Machen SK, Fisher C, Gautam RS, Tubbs RR, Goldblum JR: Utility of cytokeratin subsets for distinguishing poorly differentiated synovial sarcoma from peripheral primitive neuroectodermal tumour. Histopathology 1998;33:501-507.

-13 Pan Y, Liu WP, Li JF, Zhang WY, Li FY, Lu XX, Li D, Li GD: A clinicopathological study of 96 cases of lymphoblastic lymphoma (in Chinese). Zhonghua Xue Ye Xue Za Zhi 2005;26:218-222.

- 14 Riopel M, Dickman PS, Link MP, Perlman EJ: MIC2 analysis in pediatric lymphomas and leukemias. Hum Pathol 1994;25:396399.

-15 Robertson PB, Neiman RS, Worapongpaiboon S, John K, Orazi A: O13 (CD99) positivity in hematologic proliferations correlates with TdT positivity. Mod Pathol 1997;10: 277-282.
6 Zhang PJ, Barcos M, Stewart CC, Block AW, Sait S, Brooks JJ: Immunoreactivity of MIC2 (CD99) in acute myelogenous leukemia and related diseases. Mod Pathol 2000;13:452458.

17 Buxton D, Bacchi CE, Gualco G, Weiss LM, Zuppan CW, Rowsell EH, Huang Q, Wang J: Frequent expression of CD99 in anaplastic large cell lymphoma: a clinicopathologic and immunohistochemical study of 160 cases. Am J Clin Pathol 2009;131:574-579.

18 Hans CP, Weisenburger DD, Greiner TC, Gascoyne RD, Delabie J, Ott G, Muller-Hermelink HK, Campo E, Braziel RM, Jaffe ES Pan Z, Farinha P, Smith LM, Falini B, Banham AH, Rosenwald A, Staudt LM, Connors JM, Armitage JO, Chan WC: Confirmation of the molecular classification of diffuse large B-cell lymphoma by immunohistochemistry using a tissue microarray. Blood 2004;103:275-282.
19 Cheson BD, Horning SJ, Coiffier B, Shipp MA, Fisher RI, Connors JM, Lister TA, Vose J, Grillo-Lopez A, Hagenbeek A, Cabanillas F, Klippensten D, Hiddemann W, Castellino R, Harris NL, Armitage JO, Carter W, Hoppe R, Canellos GP: Report of an international workshop to standardize response criteria for non-Hodgkin's lymphomas. NCI Sponsored International Working Group. J Clin Oncol 1999; 17:1244.

-20 Bernard G, Breittmayer JP, de Matteis M, Trampont P, Hofman P, Senik A, Bernard A: Apoptosis of immature thymocytes mediated by E2/CD99. J Immunol 1997;158:25432550.

21 Park CK, Shin YK, Kim TJ, Park SH, Ahn GH: High CD99 expression in memory T and $\mathrm{B}$ cells in reactive lymph nodes. J Korean Med Sci 1999;14:600-606. 